\title{
A CASE STUDY ON IMPROVING STANDARDIZATION IN THE CONCEPTION PHASE BY DEVELOPING TOOLS AND PROTOCOLS
}

\author{
Martin Michaud ${ }^{1}$, Daniel Forgues ${ }^{2}$, Julien Meyer $^{3}$ and Claudiane Ouellet- \\ Plamondon 4
}

\begin{abstract}
In the Architecture, Engineering and Construction (AEC) industry, the variability nature of construction projects leads to the presence of waste. The standardization of activities and processes can help reduce variability and thus reduce the amount of waste. This paper presents an action research approach to develop and implement a framework to help creating an improved visual mapping of the information flows between the departments of an architectural firm. The aim is to use the principles of Value Stream Mapping (VSM) from Lean Production and Building Information Modelling (BIM) processes to improve standardization in the information flow.

The focus is on the information flow between the various departments of an architectural firm. This study contributes to the field through the development of a framework used to improve standardization in the information flow. Moreover, the findings presented offer practical implications by helping with the improved interoperability of interdisciplinary professionals work with standardized processes and activities.
\end{abstract}

\section{KEYWORDS}

Building Information modelling, value stream mapping, information flow, non-valueadded actions.

\section{INTRODUCTION}

Building Information Modelling (BIM) was introduced in the AEC industry with the aim to tackle the fragmentation issue by improving interoperability and collaboration among parties involved in construction projects (Eadie et al. 2014). In theory, BIM

1 Ph.D Candidate, Construction Engineering Department, École de Technologie Supérieure, Université du Québec, Montréal, CA, martin.michaud.2@ens.etsmtl.ca

2 Professor, Construction Engineering Department, Research chair for the integration of new technologies in the construction industry, École de Technologie Supérieure, Université du Québec, Montréal, CA, +1514 396-8668, daniel.forgues@etsmtl.ca

3 Postdoctoral researcher, Construction Engineering Department, École de Technologie Supérieure, Université du Québec, Montréal, CA, julien.meyer.1@ens.etsmtl.ca

4 Professor, Construction Engineering Department, École de Technologie Supérieure, Université du Québec, Montréal, CA, +1 514 396-8622, claudiane.ouellet-plamondon@etsmtl.ca 
approach is proposed as a solution to decrease fragmentation and inefficiency in the project lifecycle: it is aimed to reduce information loss by centralizing the production and exchange of information. Therefore, the concept of management of the information flow is crucial when using BIM. Indeed, BIM contributes to translating the client's value proposition into a successful project by implementing a continuous information flow (Al Hattab and Hamzeh 2013). Indeed, a holistic BIM process will smoothen information flows, but this has to go beyond merely building a BIM model. Furthermore, several barriers have been identified to explain the problems that prevent to reap the BIM benefits such as the lack of BIM coordination, the quantity and quality of information exchanged between the parties involved, the resistance to change, the lack of understanding of the entire information flows process and the lack of common shared vision (Forgues et al. 2016). The notion of information flow is not a dimension well known in construction, which is problematic for an efficient use of BIM. The notion of flow is inherent to the Lean Production approach (Koskela 2000) with several tools aimed at improving flows. Value Stream Mapping (VSM) is an essential tool used in the implementation of Lean Production to improve material, information and work flows (Rother and Shook 1999). The goal of VSM is to create a map of any productive process to identify and eliminate production waste (Braglia et al. 2011).

With an investigative method based on a collaborative design science approach (Otto and Österle 2012), this paper presents and analyzes the implementation of an approach based on Value Stream Mapping (VSM) principles generated to highlight the potential for standardization in the information flow during the design phase of construction projects. The aim of this research is to provide a framework for the firm that can be generalized for the industry, designed to help increase standardization in the information flows to reduce waste and increase the proportion of value-added activities. The focus is on the inputs and outputs of information regarding the creation of BIM models during construction projects from concept to construction drawings. It is important to note that the processes described in this paper are focused only on the BIM implementation within an architectural firm. The choice was motivated by the fact that this subject is less treated in the literature than the multidisciplinary design approach. Thus, bringing a new vision on the BIM implementation process. Furthermore, despite the presence of existing tools such as the Dependency Structure Matrix (DSM) or social network analysis, the promise of improved information flows that BIM offers is often unmet and that this provides a topic worthy of research in this paper.

\section{REVIEW}

Implementing BIM in a construction project also means moving from a documentcentric approach to an information-centric approach. BIM has been introduced in the construction industry to improve interoperability and collaboration among parties involved in construction projects (Eadie et al. 2014). However, several issues can be observed with BIM collaboration due to the quality and quantity of information exchanged between parties involved, the resistance to change, the lack of understanding of the entire information flows process and the lack of common shared vision (Forgues et al. 2016). The traditional way in construction is based on producing and exchanging information through documents. From a Lean perspective, it is also called "push planning." This kind of approach is usually done in silos with little communication with the other actors of a same process. According to Crotty (2013), a model-based design 
(information-centric approach) in the design phase will give tremendous advantages over a document-centric approach. Indeed, there is a better and earlier coordination between all the actors in the design phase, an improvement in the basic design processes giving the ability to test and analyse the design and the most important aspect is a great improvement in the quality of design information produced.

There is a need for tools to help visualize processes and related challenges with existing practices, and to identify necessary improvements. There are tools or approaches from other industries that can help to improve processes in the construction industry such as various tools adapted from Lean Production: The Last Planner System, Continuous flow, Pull System, etc. (Ansah et al. 2016). There are currently some researches focused on improving the design process and/or the information flows in construction projects. For example, Wesz et al. (2013) have conducted research related to the use of Last Planner System in the design phase with a focus on the engineer's workflow. Jacob and Varghese (2011) explored the integration of the Design Structure Matrix (DSM) in the information flows of BIM design processes. Furthermore, Al Hattab and Hamzeh (2015) presented a new strategy regarding design error management using social network analysis with a focus on team structures, error diffusion and interaction dynamics. Their aim was to compare tradition versus BIMLean practices for design error management. These researches provide frameworks to improve the design process in construction with various approaches.

Based on these results, this paper provides a new point of view to improve the information flows in the design process with a focus on the identification and reduction of sources of waste. Moreover, during the design phase, the various actors still tend to work in silo and push their information toward the next actor in the line (Aibinu and Venkatesh 2013). The traditional nature of construction projects is to provide information via documents (plans, budget, estimate, and more) through a documentcentric approach, creating barriers to communication and coordination between the different actors of the project (Isikdag and Underwood 2010). Because BIM requires an information-centric approach, the traditional push document-centric approach makes it hard to implement BIM in the design phase. This change in approach brings an interest in the Lean approach that is based on a pull planning system.

BIM and the Lean approach are two different concepts used in the construction industry. Both of them aim to the same goal that is the reduction of waste and the maximization of the value in a construction project. According to Kjartansdóttir (2011), using BIM and Lean principles, the project will have an enhanced construction process, and this will help the project team to deliver the project. Based on these observations, Moghadam et al. (2012) have been able to integrate BIM and lean construction on a modular construction manufacturing process. The authors used VSM, a tool from the Lean approach, in combination with BIM to generate a map of the factory workflow using building components' schedule. BIM provided a way to automate the design and drafting process while VSM was used to visualize the workflow and identify the source of waste, the resource usage, and the time needed.

The VSM is one of these tools available as it was developed to deal with the presence of waste in production and to help implement the Lean thinking. Indeed, the use of VSM has had a major impact in manufacturing over the years. Apart from helping to identify and eliminate sources of waste (Rother and Shook 1999), VSM also help improving productivity (Seth and Gupta 2007) and identifying opportunities for 
improvement (Singh et al. 2011). The mapping of processes is not only about material flows but also about information flows (Braglia et al. 2011). Several authors have used the VSM in construction to improve supply chains (Arbulu and Tommelein 2002), project delivery (Mastroianni and Abdelhamid 2003), component manufacturing (Alves et al. 2005) or fundamental construction process (Yu et al. 2009). While these researches provide tangible examples of how VSM can help improve construction processes, their focus is mainly put on the workflow and during the construction phase. Other researches have managed to implement VSM in construction to improve the design process (Torres et al. 2018). Through a case study, Leite and Neto (2013) used VSM to improve the information flows in housing design using Lean principles. Their case study research helped visualizing how the design process is developed. However, both of these studies' focus were limited to the identification of time waste on the design process. The notion of time waste is important in construction; however, this source of waste is only one of sources identified in construction. Indeed, authors (Howell, Koskela, Macomber, Bodek and Emond) (Emond 2014) have identified ten sources of waste in the construction context: (1) underutilization of talents, (2) waiting inputs, (3) information transfer, (4) overproduction of information, (5) deficient behaviour, (6) loss of good ideas, (7) achievements unappreciated by the client, (8) make-do, (9) resistance to change and (10) non-management of perception. The authors Aka et al. (2017) have carried out a research on the identification of waste in the design phase using VSM. Their study focused on the engineering and stopped at the current state with the identification of waste and recommendation of strategies to reduce waste. Based on the researches discussed in the review, this paper aims to fill a gap in knowledge by providing an approach using VSM to identify the ten known sources of waste in the information flows of the design process of an architectural firm. Furthermore, VSM is used to help provide a new approach in the implementation of BIM by identifying and reducing existing waste beforehand.

\section{METHODOLOGY}

The methodology used for this research was a collaborative design science approach (Otto and Österle 2012). The aim of this research is to identify activities or information within the design process of an architectural firm possible to standardize between projects to reduce the presence of waste within the information flows. The research protocol was based on VSM mapping exercise to help the members of the BIM core to visualize and better understand their own work and information flows process as well as the processes of the other department in order to formalize a unique and shared framework to manage the information processing. The VSM technique was not used in its entirety in this research. Only the VSM principles to map the processes and identify the wastes were used. The mapping used the standard Business Process Model and Notation (BPMN) to represent accurately and consistently results for each department. BPMN helped to facilitate the understanding of the maps as it provides a standard notation readily understandable by all stakeholders of a project. It was only used as a graphical representation and did not impact the principles of VSM used during this research. This research is organized and separated into three main steps: 1) thinking, 2) operationalization, 3) diffusion (Figure 1). Within each step of the research, a cell composed of members of the architectural firm is implicated in the process. 


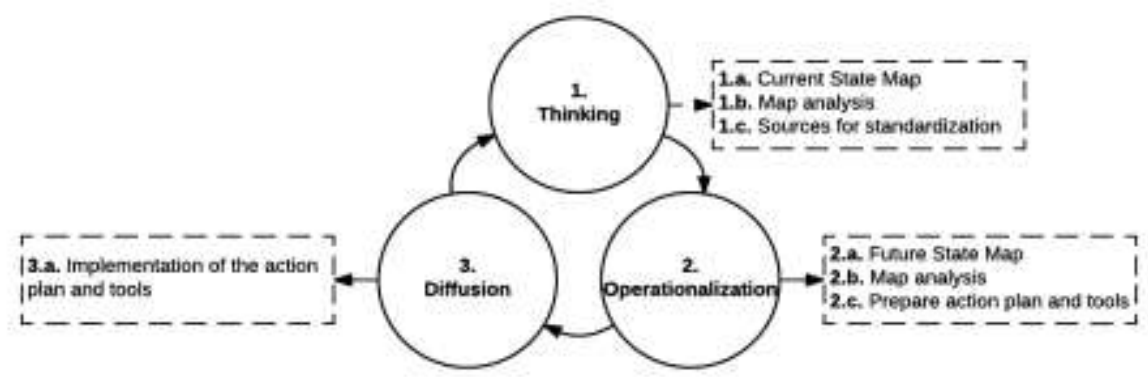

Figure 1: Approach based on VSM used during the research: The role of each cell is to help provide data and information during each step of the process.

The data was collected from an architectural firm focusing on building projects, such as residential buildings or shops. The first stage, current state map creation, occurred from September 2016 to December 2016 through nine focus groups; composed of one focus group per department, and four for the architectural department because four different building projects have been studied. Each focus group was conducted with several members of the department involved, such as directors of departments, project managers, architects, engineers, designers with one facilitator performed by one of the researchers of this paper. The focus groups were consulted twice during $1.5 \mathrm{~h}$ interviews: the first for the creation of the map and the second for comments with a total of nine maps created. For the second stage from January 2017 to June 2017, the data collected from the previous phase was used to help prepare an action plan with templates and tools. Five focus groups were conducted with several members of each department as the same manner as during the first phase. During the third and last stage from July 2017 to September 2017, a standardization manual was produced, based on the results from the two previous stages. The manual was distributed to the departments of the architecture firm to inform of the new standardized protocols.

\section{PRELIMINARY RESULTS}

\section{THINKING}

The first objective of the Thinking step was to create a current state map of the internal information flows of the various departments of an architectural firm during the design stage of a construction project. The cell responsible to run this step was composed of ten members of the firm and one member was responsible for writing down the minutes of every meeting to resume and communicate the information to all the members of the cell. At least one member of each department of the firm was represented in the cell to obtain accurate information from the entire firm. The use of VSM helped the cell mapping the information flows with a set of rules and then helped identify potential sources of information that could be standardized. The figure 2 shows a section of the current state with a highlight of the architectural department realized with the help of the architects. This figure aims to show a typical information flow between the client and the architectural department during the design process at the firm. At this moment, the firm is still using AutoCAD and 2D drawings, as they are currently working on the implementation of BIM. The aim of this mapping exercise was to highlight the input of information needed from the client to produce the drawings, plans or models and then highlight the output of information given by the plans to meet the client's needs. After being refined, the figure 2 shows a process map identifying the input and output of 
information around the plans created during the design phase. Indeed, several projects were mapped to obtain the most common information exchanges in the firm's projects. The output of information created by the architectural department may correspond to the input of information needed by the other departments, such as engineering to complete their activities.

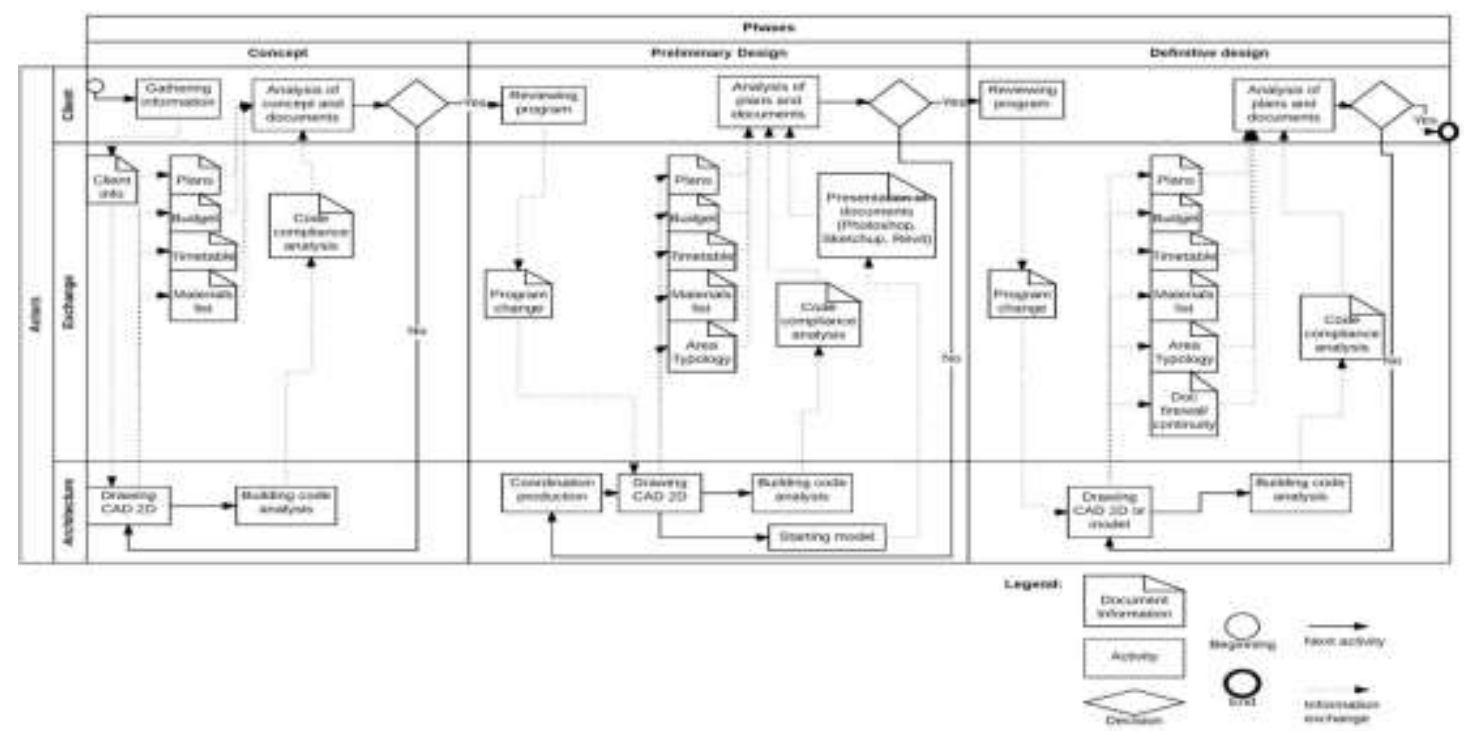

Figure 2: Current State Map of the architectural information flows in the design phase.

The information and documents show information present in each project studied (lists of materials, timetables, budgets or plans). The same analysis was done for the other departments of the firm to determine two points. First, the kind of information or documents that can be standardized from one project to another within each department. Second, from these information and documents identified, which ones can be standardized globally and used by each department in the firm. This paper focuses on the second point and presents several sources of information that can be standardized for all the departments of the firm such as the level of detail between the phases or estimation reports. Furthermore, the Thinking cell, responsible for the first step of the research established the criteria and parameters for each source identified. These criteria were then transferred to the second cell responsible for the operationalization step.

The first analysis phase has resulted in the identification of eight potential sources of information that can be standardized. The criteria and parameters needed for each source are described below:

- Level of Detail (LOD): Templates must be created to determine the LOD of the model for each step of the design phase (concept, preliminary design and definitive design).

- Template: Several points were discussed regarding the templates of all the documents that are created during the research. First, the goal is to obtain a unique template, however, because of the construction market in Quebec, two templates were created with one using the metric system and the other the imperial system. Second, the template was created on Revit 2016 after a 
comparison was made with Revit 2015. Third and finally, the language used for the development of the templates was determined to be the French.

- Dividers and doors tables: Graphical representation for three-level wall types are accepted by all departments. A quality control template in the architecture department needs to be incorporated into the metric template. A table of hardware needs to be inserted in a standard format with the template. A table of doors need to be inserted in the template including all possible elements composing a door.

- Materials: symbols, tables and other information must be defined for each department to keep it constant from one project to another or when the model is used by several departments in the firm.

- Zoning plans: In the Revit template, a table must be created to compare the surfaces indicated in the Design brief from the client and the surfaces modelled. Moreover, the operationalization cell must find a way to the design brief data sheets to the concordant parts in the model.

- Estimate: During the design phase, there is a need for three different estimates. First, during the concept, the estimate must be made in square feet, the unit prices come from Means' database and the costs are calculated according the applications of the project and its usages. Second, during the preliminary design, the estimate must be done with the system Uniformat and generic walls are used for the estimate. Third, during the definitive design, the estimate is made with the system Uniformat with a high level of accuracy and all the walls types are defined.

- Coordination per phases: The conclusion on this topic is that there is a need to develop views or a system to coordinate plans between the various stakeholders internally and/or externally from the Revit model.

- BIM management plan: The BIM management plan is being developed by the diffusion cell in accordance with the results and documents obtained from the other sources.

\section{OPERATIONALIZATION}

The role of the operationalization cell was to format the template from the criteria and parameters identified by the thinking cell. The cell was composed of ten members of the firm and had the same configuration as the Thinking cell. Furthermore, the cell was responsible to fill the LOD matrix for the whole firm while waiting for the criteria from the reflection cell. The LOD matrix was the first task completed during the operationalization with a study of various references and a formation received by an external firm. The LOD matrix adopted during the research was used regarding every source standardized. Indeed, the design phase in the construction projects of this firm is usually divided into three parts - concept, preliminary design and definitive design and the LOD of the Revit model is different in each of these parts. A LOD standardization will help normalize the input and output of information, thus, limiting the presence of waste regarding overproduction of information or loss of information because each actor will know the kind of information they need to produce in the model for each phase. 
Regarding the dividers and doors' tables and materials, a standardized data bank was created and must regularly updated to allow actors to understand information coming from another department and increase their productivity by gaining time creating models from one project to another. Meetings were necessary between the engineering and the architect departments to coordinate on the families' creation for plumbing and lighting in Revit to standardize their input in the models. Indeed, a nomenclature of Revit families was proposed and adopted based on the needs of each department.

Every change implemented during this step still must be tested in practice. Indeed, this protocol was implemented to facilitate the implementation of BIM in the near future. The standardization of activities and information will help give a better understanding of BIM processes and Revit to the users and finally help the firm limit the presence of waste in the information flows.

\section{DIFFUSION}

The first step of the diffusion cell was to identify the existing templates for each department. The cell was composed of seven members of the firm and had the same configuration as the other cells. Moreover, there was a need to identify all the training tools available for Revit software, as most of the projects are currently still done with AutoCAD. During the meetings organized with the diffusion cell, there was a consensus regarding the creation of a training manual serving both to train all the employees on the BIM processes, but also on the Revit software and on the processes by departments. The thinking therefore revolved around the design of a single manual, which establishes BIM procedures. Sections of the manual present specificities per department and a section is devoted to the training of the Revit software. This manual is going to be available on the Intranet of the firm. To share knowledge and keep a continuous improvement, the use of a platform such as Trello or Asana (to be evaluated) is necessary.

Work is still in progress within this cell to create an internal BIM management plan and standard documents that are going to be used by each department for the future BIM projects. This research has given the opportunity for the architectural firm to develop standard tools that will benefit them. Moreover, the results of this research are going to be published to provide a framework on how to increase standardization in the design phase to reduce the presence of waste at the source of a construction project with the use of VSM principles. Furthermore, the approach used during the research will be repeated in the future to identify more potential sources of information that could be standardized in future projects: this protocol can be used as a form of continuous improvement.

\section{CONCLUSIONS}

This collaborative design science research uses VSM from lean production to improve standardization in the information flows of the design phase in construction projects. This research aims to facilitate the transfer from a traditional practice to a BIM approach. Because of the tendency that stakeholders have, to keep using a documentcentric approach by pushing information they created to the next actor, the BIM implementation usually presents some contradictions and issues with the information processing. This case study provides a clear view that, despite the fragmented nature of 
construction projects and the lack of repetition in the production process, VSM can be implemented to improve standardization in the design process to limit the creation of waste in the information flows such as overproduction of information. This case study demonstrated the need to improve the information flows in the design phase by increasing standardization. Furthermore, despite the fragmented nature of the construction industry, it is possible to implement standardization on some level in the design phase to improve coordination and reduce waste within the information flow of the design process.

Future work regarding this research should be to complete several iterations of the framework to identify more potential sources for standardization. Moreover, the future discussion will not only focus on the architectural information flow but will integrate several departments of the firm to demonstrate that standardization of the information flow is possible between various actors of a same process. The project will provide a complete and accurate future state map of the information flows in the design phase of construction projects.

\section{REFERENCES}

Aibinu, A., and Venkatesh, S. (2013). "Status of BIM adoption and the BIM experience of cost consultants in Australia." Journal of Professional Issues in Engineering Education and Practice, 140(3), 04013021.

Aka, A., Emuze, F., and Das, D. "Mapping Waste in the Structural Design Process in South African Projects " Proc., 25th Annual Conference of the International Group for Lean Construction, pp. 475-482.

Al Hattab, M., and Hamzeh, F. "Information Flow Comparison Between Traditional and BIM-Based Projects in the Design Phase." Proc., Proceedings for the 21st Annual Conference of the International Group for Lean Construction, pp. 761770.

Al Hattab, M., and Hamzeh, F. (2015). "Using social network theory and simulation to compare traditional versus BIM-lean practice for design error management." Automation in construction, 52, pp. 59-69.

Alves, T. D. C., Tommelein, I. D., and Ballard, G. (2005). "Value stream mapping for make-to-order products in a job shop environment." Construction Research Congress 2005.

Ansah, R. H., Sorooshian, S., Bin Mustafa, S., and Duvvuru, G. "Lean Construction Tools." Proc., Proceedings of the 2016 International Conference on Industrial Engineering and Operations Management.

Arbulu, R. J., and Tommelein, I. D. "Value stream analysis of construction supply chains: case study on pipe supports used in power plants." Proc., Proceedings IGLC, pp. 183-195.

Braglia, M., Carmignani, G., and Zammori, F. (2011). "A new value stream mapping approach for complex production systems." International journal of Production Research, 44(18-19), pp. 3929-3952.

Eadie, R., Odeyinka, H., Browne, M., McKeown, C., and Yohanis, M. (2014). "Building Information Modelling Adoption: An Analysis of the Barriers to Implementation." Journal of Engineering and Architecture, 2(1), pp. 77-101. 
Emond, C. (2014). "SlideShare - L'AgiLean (Agile + Lean) à la rescousse de tous nos projets (publics et autres)." <https://fr.slideshare.net/claudee/gp-qubec2014agileance>. (15 February 2015).

Forgues, E. C., Carignan, V., Forgues, D., and Rajeb, S. B. "A framework for improving collaboration patterns in BIM projects." Proc., International Conference on Cooperative Design, Visualization and Engineering.

Isikdag, U., and Underwood, J. (2010). "Two design patterns for facilitating Building Information Model-based synchronous collaboration." Automation in construction, 19, pp. 544-553.

Jacob, J., and Varghese, K. (2011). "Integratation of BIM and DSM to improve design process in building construction projects." 13th International Dependency and Structure Modelling Conference, DSM'11Cambridge, Massachussetts, USA, pp. 363-368.

Kjartansdóttir, I. B. (2011). "BIM adoption in Iceland and its relation to lean construction." Master of science thesis, School of Science and Engineering at Reykjavík University.

Koskela, L. (2000). "An exploration towards a production theory and its application to construction." Ph.D., Helsinki University of Technology.

Leite, K. P., and Neto, J. d. P. B. "Value Stream in Housing Design " Proc., 21th Annual Conference of the International Group for Lean Construction, pp. 419-428.

Mastroianni, R., and Abdelhamid, T. "The challenge: The impetus for change to lean project delivery." Proc., 11th Conf. of Int. Group for Lean Construction, pp. 418-426.

Moghadam, M., Alwisy, A., and Al-Hussein, M. (2012). "Integrated BIM/Lean Based Production Line Schedule Model for Modular Construction Manufacturing." Construction Research Congress 2012: Construction Challenges in a Flat Word.

Otto, B., and Österle, H. (2012). "Principles for Knowledge Creation in Collaborative Design Science Research." Thrity Third International Conference on Information SystemsOrlando, USA.

Rother, M., and Shook, J. (1999). "Learning to see." Lean Enterprise Institute, Cambridge, $M A$.

Seth, D., and Gupta, V. (2007). "Application of value stream mapping for lean operations and cycle time reduction: an Indian case study." Production Planning \& Control: The Management of Operation, 16(1), pp. 44-59.

Singh, B., Garg, S. K., and Sharma, S. K. (2011). "Value stream mapping: literature review and implications for Indian industry." International Journal of Advanced Manufacturing Technology, 53(5-8), pp. 799-809.

Torres, L. A., Sonza, M. C. S., Xavier, A. C. B., and Melo, R. S. S. (2018). "Value Stream Mapping of the Design Process in a Design-Build Firm." 35th International Symposium on Automation and Robotics in Construction (ISARC 2018)Berlin, Germany.

Wesz, J. G. B., Formoso, C. T., and Tzotzopoulos, P. (2013). "Design process planning and control: last planner system adaptation." 21th Annual Conference of the International Group for Lean ConstructionFortaleza, Brazil, pp. 369-378. 